\title{
Damage analysis and integrity assessment of a few steam-reformer components at a syn-gas plant
}

\author{
Bhupendra Gaur* \\ Corrosion Consultant, 701, Landmark Building, Plot No. D2, Sector 12, Kharghar, Navi Mumbai 410210 , India
}

Received: 16 March 2016 / Accepted: 8 February 2017

\begin{abstract}
Study deals with damage-analysis and integrity-assessment for a few components of a steamreformer at a syn-gas generation plant, including catalyst tubes and hot-collectors. Selected components include the ones which either suffered from a fluid-leakage in the service or noticed with a constant high-temperature exposure during normal plant operation. The field investigation activities included visual inspection, dimensional check, die-penetrant test and pressure-drop measurements. Laboratory investigation, made on selective samples, included precise and detailed dimensional-measurement, visual examination, die penetrant test, microstructural characterization, creep-rupture test, etc. As a result of diagnostic analysis, creep was identified as the principal mechanism of degradation of the studied components. Catalyst tubes were found to be in sound condition and, hence, recommended to continue in use for the remaining period of the service-life, even after high-temperature exposure in the past. Other items; however, were noticed with a limited residual creep strength, hence, rejected for future use. Further, recommendations were made for improvement in practices of process- and operation-management, to avoid pre-mature deterioration of the reformer components. In addition, suggestions were given for enhancing the versatility and reliability of plant inspection and monitoring methods, using latest tools and technology of the field. Moreover, suitability and limitation of different analytical approaches regarding interpretation of test and inspection results are highlighted.
\end{abstract}

Keywords: steam reformer / catalyst tube / HP modified alloy / creep / integrity assessment / failure analysis

\section{Introduction}

Steam reformer is a vital, costliest and most critical equipment of a petrochemical plant. It is mostly used to produce hydrogen rich gas to form methanol or ammonia from the reaction of hydrocarbons with steam in presence of a catalyst. Generally, hydrocarbon is a natural gas with methane as the principal constituent. The basic reaction may be represented by the following simple equations:

$$
\begin{gathered}
\mathrm{C}_{n} \mathrm{H}_{m}+n \mathrm{H}_{2} \mathrm{O} \rightarrow n \mathrm{CO}+\left(\frac{m}{2}+n\right) \mathrm{H}_{2} \\
\mathrm{CO}+\mathrm{H}_{2} \mathrm{O} \rightarrow \mathrm{CO}_{2}+\mathrm{H}_{2}
\end{gathered}
$$

The reforming reaction is of highly endothermic nature as the number of moles of the product exceeds the number of moles of the reactants. Hence, a large amount of heat energy is required to drive the reaction process. In reforming furnace, this is facilitated in the catalyst-filled tubes (called "catalyst tubes") which are continuously fired at their outer surface.

\footnotetext{
* e-mail: bhupendragaur@hotmail.com
}

There has been a constant improvement in the reformer's performance to boost up plant-productivity, by advancements in the catalyst and process technology. The best performance is achieved at a steam-to-hydrocarbon ratio of around $3: 1$, temperature of about $850^{\circ} \mathrm{C}$ and pressure of about $20 \mathrm{~kg} / \mathrm{cm}^{2} \mathrm{~g}$, simultaneously [1]. Elevation in service conditions; however, has an adverse impact on the mechanical and metallurgical integrity of the furnace components, particularly its catalyst-tube assembly. The latter is the most critical part of a reformer compared to other ones and amounts to be about $25 \%$ of the total equipment cost. The high temperature causes an axial stress in the body of a catalyst tube and associated piping leading to a longitudinal creep. While, high pressure creates a hoop stress which develops a circumferential creep on these items. Thus, both kind of stresses reduce the life of the reformer components, because of the creep damages. Creep process may usually involve three distinct stages namely primary, secondary and tertiary described elsewhere [2]. In case of normal creep damage, material undergoes time-dependent plastic deformation that leads to changes in the component's dimension, e.g., bulging. In case of advanced creep damage, strain-rate drastically increases with a rapid action to cause a fracture, through voids and cracks. Creep rupture cracks are usually 
associated with secondary cracks as well. To minimize these problems, the material of reformer tube-assembly is chosen with a sufficient resistance to high temperature, high pressure, creep, attack of fuel contaminants, etc., i.e. with a high creep rupture strength [2-5]. However, exceeding of service parameters beyond their design limits due to either a process excursion or an operational anomaly, results in the diminution of reformer's service-life as well as enhancement in the plant-maintenance load. Process excursion and operation anomaly can be a result of catalyst degradation (activityloss) and burner de-alignment (flame impingement), respectively. Plant maintenance load is appreciably increased by metallurgical- or mechanical-damages at the reformercomponent, i.e. creep, thermal shock, overheating and carburization of metal, etc. [3]. It is further reported [4] that most of the pre-mature failure of reformer-tubulars are caused by overheating which leads to a creep damage and service ageing which leads to an embrittlement.

In order to withstand metallurgical challenges caused by a constant aggravation in process conditions of the steam reformer, there has been a continual improvement in its materials technology regarding alloy-development and manufacturing processes, in last three decades. Owing to their good creep-rupture strength and corrosion (oxidation) resistance, high-alloy austenitics are naturally chosen as a construction material (MOC) for the reformer constituents, e.g., inlet and outlet piping, burners, catalyst tubes, etc. In 1980 s, HP (25Cr-35Ni) modified alloys were developed for the catalyst tubes, using certain metallic additives, such as molybdenum, niobium, titanium, and tungsten [6-8]. These alloys possess highly stabilized carbides; high mechanical and creep-rupture strength; good oxidation resistance; improved thermal shock and stress resistance; good ductility and weldability; high durability, etc. Niobium in HP alloys enhances carburization resistance in addition to creep strength as reported in case of alloy HK-40 [8]. In a separate development, HP micro-alloyed with a trace addition of titanium, zirconium and rare earths (during casting) also gave similar improvements [7]. Nonetheless, advanced alloys also suffer deterioration when exposed to an aggressive plant condition for a measurable duration, i.e. over-heating [8,9]. Present paper deals with damage-analysis and integrity-assessment for a few components of a steam-reformer at a syn-gas generation plant. Selected components include the ones which either suffered from a fluid-leakage in the service or noticed with a constant hightemperature exposure during normal plant operation. In general, these were parts of different catalyst-tube assemblies and made of high alloy austenitics.

\section{Background}

A reformed-gas outlet sub-header called "hot-collector", of a reformer namely "reformer-2", ruptured catastrophically at a weldolet connection to a catalyst-tube. This caused fluidleakage within a short period of $5 \frac{1}{2}$ years of equipment's commissioning into the service. As per information from the plant personnel, excessively high temperature was constantly noticed at the affected hot-collector as well as attached catalyst-tube, during routine condition-monitoring of the equipment when plant was under normal operation. Also, bulging was observed at a few catalyst-tube ends including short-piece and pig-tail. As a result, emergency shut-down of plant was undertaken and about $500 \mathrm{~mm}$ length of hotcollector was replaced, as a temporary maintenance measure. Within about a year, however, all hot-collectors with a number of catalyst-tube assemblies were completely replaced, as a permanent measure, on precautionary basis. The replaced tube-components generally included the items which were observed with a higher "tube-skin temperature" called "TMT" in the running plant or the ones found with a higher bulging-rate during shutdown inspection. In order to explore the cause of damage for failed (cracked or deformed) items as well as to assess the integrity-status for suspected (heat exposed) items, a few reformer components were subjected to detailed lab investigation. Lab analysis involved visual examination, precise dimensional measurements, metallurgical characterization and mechanical-testing. The results of study, conducted both in lab or in field, will be collectively dealt in the forthcoming sections, before drawing any conclusion. For a better understanding of the studied system, basic details of reformer-2 are summarized below:

\section{General}

Type Box type, top fired

Temperature - Service, Inlet $-530^{\circ} \mathrm{C}$ and outlet max. $\quad 873{ }^{\circ} \mathrm{C}$

Temperature - Design Inlet $-545^{\circ} \mathrm{C}$ and outlet $893^{\circ} \mathrm{C}$

Pressure - Service Inlet $-22 \mathrm{~kg} / \mathrm{cm}^{2} \mathrm{~g}$ and outlet $-19 \mathrm{~kg} / \mathrm{cm}^{2} \mathrm{~g}$

Pressure - Design Inlet $-24 \mathrm{~kg} / \mathrm{cm}^{2} \mathrm{~g}$ and outlet $-24 \mathrm{~kg} / \mathrm{cm}^{2} \mathrm{~g}$

Fuel type

Inlet system and

material

Outlet system type

Natural gas

Manifold type $1 \frac{1}{4} \mathrm{Cr}-\frac{1}{2} \mathrm{Mo}$

Pigtail material

Collection header

material

Burner type and

material

Pigtail type with collection header

$20 \mathrm{Cr}-32 \mathrm{Ni}$ (Incoloy $800 \mathrm{HT}^{\circledR}$ )

$20 \mathrm{Cr}-32 \mathrm{Ni}-\mathrm{Nb}$ (Kubota Alloy KHR32C ${ }^{\circledR}$ )

Forced draft (single gas tip), Inconel $^{\circledR} 600$

\section{Catalyst tube}

Arrangement

Number of tubes

Length

Inner diameter and thickness

Material of

construction

Tube support

Service temp. and

pressure

Design temp. and

pressure

Vertical
Over 600
$14 \mathrm{~m}$
110 and $9.7 \mathrm{~mm}$, respectively
$25 \mathrm{Cr}-35 \mathrm{Ni}-1.5 \mathrm{Nb}-\mathrm{Ti}$ micro
alloy $(\mathrm{Kubota}$ Alloy KHR35CT
Top, variable spring hanger
$893^{\circ} \mathrm{C}$ and $22 \mathrm{~kg} / \mathrm{cm}^{2} \mathrm{~g}$
maximum, respectively
$945^{\circ} \mathrm{C}$ and $24 \mathrm{~kg} / \mathrm{cm}^{2} \mathrm{~g}$,
respectively

\section{Over 600}

$14 \mathrm{~m}$

$25 \mathrm{Cr}-35 \mathrm{Ni}-1.5 \mathrm{Nb}-\mathrm{Ti}$ micro alloy(Kubota Alloy KHR35CT ${ }^{\circledR}$ ) $893{ }^{\circ} \mathrm{C}$ and $22 \mathrm{~kg} / \mathrm{cm}^{2} \mathrm{~g}$ maximum, respectively respectively 


\section{Inspection, testing and characterization}

In view of the rupture of a hot-collector, reformer-2 was subjected to detailed inspection and testing during plant-shutdown, within one year of event's occurrence. The key objectives of this comprehensive condition checkup were:

- to ensure safe and reliable operation of the reformer;

- to closely estimate the magnitude of repair and maintenance job;

- to establish the criteria of replacing a reformer component, e.g., catalyst-tube, short piece, pig tail, header, etc.

In addition, the history of operation and maintenance was recorded to correlate it with the observations and data collected during the plant inspection. Such information could also assist during interpretation of the lab investigation results.

\subsection{Field inspection and measurements}

For catalyst tubes, visual inspection, catalyst pressure-drop $(\Delta P)$ measurement and dimensional check were carried out. For selective tubes, results are given in Table 1. From the obtained data, it was evident that many catalyst tubes had high pressure-drop thereby indicating measurable agglomeration and pulverization of the catalyst inside a tube. Most probably, this could have occurred due to attack of steamcondensate on the catalyst. Further, it was anticipated that that some of the tube-sections had undergone extreme hightemperature exposure as these showed the sign of creep deterioration in the form of bulging and cracking. This observation was in consistent with high TMT noticed in the reformer when plant was under normal operation. Else, one short piece had a bulging of about $11.4 \%$ and also observed with almost penetrating cracks.

\subsection{Lab inspection and testing}

For the selective reformer components, which either had history of high TMT when plant was under operation or the ones noticed with a damage during equipment inspection, lab investigation was also carried out. Main purposes of conducting lab study were to explore the root cause of damage in case of failed items and to assess the remaininglife in case of thermally affected items. The techniques used in lab study included visual test "VT", die penetrant test "PT", dimensional measurement, macro- and microstructure analysis and creep rupture test. The results of lab inspection and testing are given in Tables 2 and 3 .

\section{Diagnostic analysis}

\subsection{Catalyst tubes}

The tubes, which were noticed with a higher TMT during operation, were expected to suffer from some bulging. During field inspection; however, it was found that there was no proper correlation between the measured tube perimeter and high TMT exposure. For example, tube RD-30 (not shown in above table) had perimeter of
$421.4 \mathrm{~mm}$ but had no sign of high temperature and high catalyst $\Delta P$. The bulging at its short piece was also below $2 \%$. In contrast, tube RG-21, which had all signs of high temperature such as high TMT, high catalyst $\Delta P$ and high bulging of $6.5 \%$ at the short piece, did not show the sign of bulging at the tube as per measured perimeter. The literature; however, suggests that the life assessment of a catalyst tube based on the outer dia inspection with no previous baseline measurement may be conservative $[10,11]$.

As per visual inspection, tubes having exposed to high temperature, had smoother outer surface as compared to normal heated ones. The latter had a rough surface with a ceramic scale or soot. This observation could be due to removal of the scale from these tubes by high temperature oxidation. This could be the explanation for the inconsistency between high temperature exposure and perimeter of the catalyst tubes, observed in different cases.

From precise measurements as well as macro- and micro-structural analysis (Tab. 2 and Fig. 1), the comparison of inner diameter shows apparent bulging for RI-1 only. This tube could have really been exposed to a very high temperature and had about $2 \%$ bigger inner diameter. The location of tube RI- 1 is in coincidence with the leakage incidence occurred earlier that could also be linked to a high-temperature exposure, apparently. The other tubes, including those having even more bulging at short piece and high $\Delta P$, showed no appreciable difference in the inner diameter.

Figure 1 shows the macro- and micro-structure photographs for the bottom section of the RI-1 tube, indicating the sign of real bulging and high temperature. The coalescence and coarsening of the secondary carbides is more remarkable than the others, which again endorses the possibility of long-term high temperature exposure of these tubes. However, creep voids are not so remarkable, which means that there is no significant deterioration of the metal. For other tube samples also, same observation was made, regarding metallurgical integrity. Table 2 highlights important features such as secondary carbides (coalescence and coarsening) an index of exposure to high temperature, creep defects an index of the deterioration of metal, etc., for different tubes with a rating.

For a quantitative assessment of tube's remaining life, creep rupture test was undertaken, as per following details and results are shown in Figure 2:

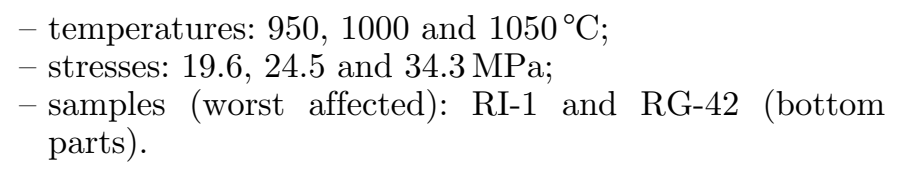

The stress rupture data have been plotted in terms of stress versus LMP (Larson-Miller parameter).

$$
\mathrm{LMP}=\left[273.15+T\left({ }^{\circ} \mathrm{C}\right)\right] \times[C+\log t] \times 10^{-3}
$$

where $T$ is the temperature in ${ }^{\circ} \mathrm{C}$ and $C$ is a constant. For used cast alloy for catalyst tube, its value is 20 and $T$ is the rupture time, in hours. 


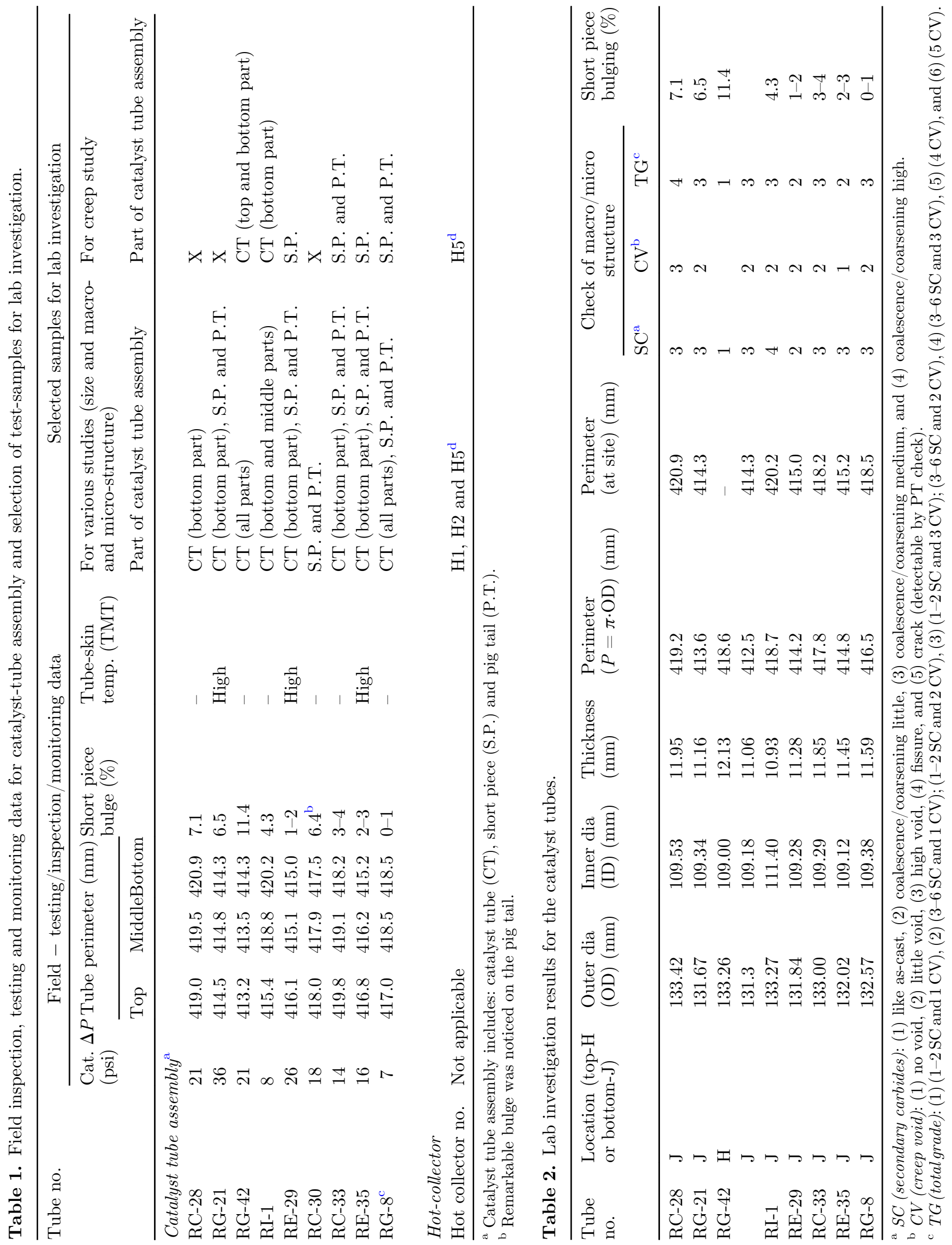


Table 3. Lab investigation results for the short-piece and the pig-tail.

\begin{tabular}{|c|c|c|c|c|c|c|c|}
\hline \multirow[t]{2}{*}{ Tube no. } & \multirow[t]{2}{*}{ Section $^{a}$} & \multirow{2}{*}{$\begin{array}{l}\text { Outer dia } \\
\text { average }(\mathrm{mm})\end{array}$} & \multirow{2}{*}{$\begin{array}{l}\text { Thickness } \\
\text { average (mm) }\end{array}$} & \multicolumn{2}{|c|}{ Bulging (\%) } & \multirow[t]{2}{*}{ PT rating ${ }^{\mathrm{b}}$} & \multirow{2}{*}{$\begin{array}{l}\text { Macro/micro } \\
\text { structure rating }\end{array}$} \\
\hline & & & & At lab & At site & & \\
\hline \multirow[t]{2}{*}{ RG-42 } & S & 47.08 & 4.47 & 11.6 & 11.4 & 5 & 5 \\
\hline & $\mathrm{P}$ & 43.70 & 4.91 & 3.5 & 4.0 & 5 & 5 \\
\hline \multirow[t]{2}{*}{ RI-1 } & S & 43.71 & 4.64 & 3.6 & 4.3 & 3 & 3 \\
\hline & $\mathrm{P}$ & 42.98 & 5.03 & 1.8 & 2.3 & 2 & 3 \\
\hline \multirow[t]{2}{*}{ RE-29 } & S & 42.84 & 4.75 & 1.5 & $1-2$ & 2 & 2 \\
\hline & $\mathrm{P}$ & 42.42 & 5.10 & 0.5 & - & 2 & 1 \\
\hline \multirow[t]{2}{*}{$\mathrm{RC}-30$} & S & 45.82 & 4.41 & 8.6 & 6.4 & 5 & 5 \\
\hline & $\mathrm{P}$ & 44.51 & 4.95 & 5.5 & 5.3 & 5 & 5 \\
\hline \multirow[t]{2}{*}{ RD-19 } & S & 44.09 & 4.61 & 4.5 & 4.7 & - & - \\
\hline & S & 43.64 & 4.64 & 3.4 & & 4 & 5 \\
\hline \multirow[t]{2}{*}{$\mathrm{RC}-33$} & S & 43.80 & 4.63 & 3.8 & $3-4$ & 3 & 3 \\
\hline & $\mathrm{P}$ & 43.12 & 5.00 & 2.2 & 1.9 & 4 & 3 \\
\hline \multirow[t]{2}{*}{ RI-2 } & S & 43.09 & 4.65 & 2.1 & 3.6 & - & - \\
\hline & S & 43.66 & 4.60 & 3.4 & & 2 & 2 \\
\hline \multirow[t]{2}{*}{ RE-35 } & S & 42.91 & 4.70 & 1.7 & $2-3$ & 1 & 2 \\
\hline & $\mathrm{P}$ & 42.37 & 5.13 & 0.4 & - & 1 & 2 \\
\hline \multirow[t]{2}{*}{ RG-8 } & S & 42.68 & 4.81 & 1.1 & $0-1$ & 1 & 1 \\
\hline & $\mathrm{P}$ & 42.35 & 5.09 & 0.4 & - & 1 & 1 \\
\hline
\end{tabular}

a Section: "S" - short piece and "P" - pigtail stub.

b PT: (1) no crack, (2) little cracks (only at in/out surface), (3) little cracks (in metal also), (4) medium cracks (in metal also), and (5) significant crack (almost penetrating).

${ }^{c}$ Macro/micro structure: (1) only surface (in/out) oxidation, (2) creep voids in metal, (3) creep fissures in metal, (4) creep fissures in metal and significant cracks in surface, and (5) cracks all through metal.

The minimum rupture-strength curve for the virgin catalyst tube material "Kubota's HP-Nb alloy" is shown for the reference. These plots show obvious loss of creep life in terms of creep strength after use of 7 years. For actual construction, having $109.2 \mathrm{~mm}$ ID and $11.5 \mathrm{~mm}$ thickness at abovementioned operating conditions, remaining life remains still appreciable. However, considering virgin material basis, the remaining life is estimated to be about $29 \%$ for RG-42 (good) and 3\% for RI-1 (worst), respectively. Thus, good tubes can be considered to complete the remaining design life (about 3 years).

\subsection{Short piece and pigtail}

From Table 3, it is evident that the results of dimension check as well as identifications and revelations of other damages in the lab including cracking, metallurgical deterioration, etc., are in close agreement with the site inspections and evaluations, in most of the cases. A few of them are highlighted in below:

- RG-42 with bulging of $11.4 \%$ had remarkable cracks both in pipe piece as well as in weld-joint with the reducer;

- RD-19 with bulging of $4.7 \%$ had slight crack in the pipe but had no crack in the weld-joint;

- RI-2 with bulging $3.6 \%$ had no crack both in the pipe and in the weld-joint.
The degree of bulging and metallurgical deterioration assessed in terms of macro- and micro-structural deformation appear to be proportional. The items bulged over $4 \%$ seem to have an appreciable damage, but below ones not to have. Figure 3 shows the typical results of $\mathrm{PT}$ inspection as well as macro- and micro-analysis for the short piece of tube RI- 1 which had a bulging of $4.2 \%$. The same is observed to be applicable to the connected pigtails.

Creep rupture tests were performed for the short piece and pigtails stubs of tube number RE-29/RC-33/RE-35/ RG-8 and RC-33/RG-8, respectively, at the following conditions:

- temperature: 850,900 and $950^{\circ} \mathrm{C}$;

- stress: 16, 24.5 and $35 \mathrm{MPa}$;

The results of above tests for short piece are given in Figure 4, and important observations are highlighted in forthcoming discussion. In spite of some indication of $\mathrm{PT}$ and presence of creep fissure, the short piece of RC-33 with bulging of $3.8 \%$ showed almost negligible deterioration compared to virgin alloy $800 \mathrm{H}$. The other short pieces with less bulging showed no sign of deterioration. The pigtail stub of RC-33 had appreciable voids, but showed no sign of deterioration.

The estimated remaining life of RC-33 short piece for actual construction and operating conditions comes out to be significant, say about $310000 \mathrm{~h}$. This is not strange because alloy $800 \mathrm{H}$, as a wrought steel, has some endurance 


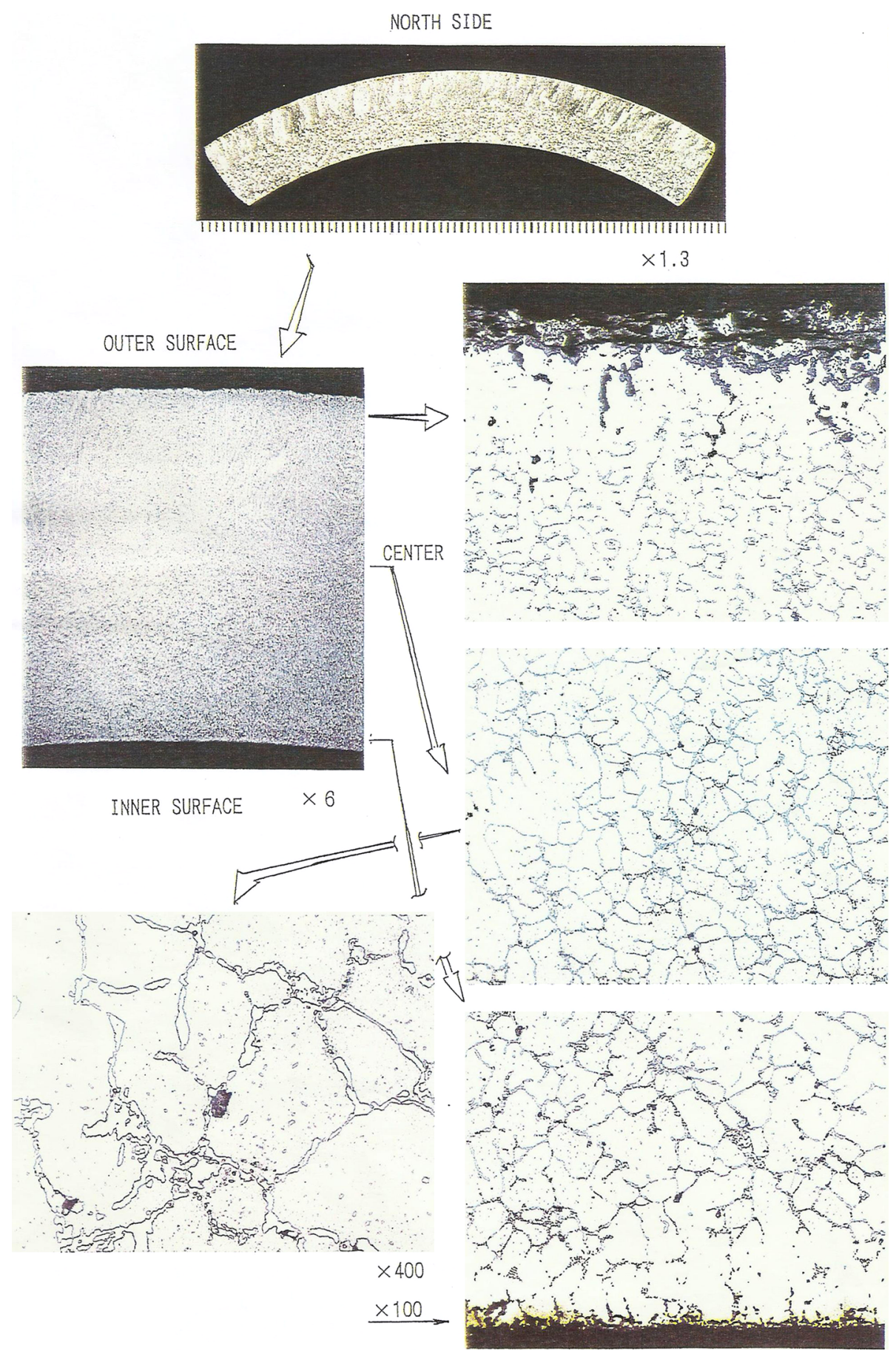

Fig. 1. Macro- and micro-structure of the bottom section of RI-1 catalyst-tube.

after the creation of creep voids and fissures. It should also be noted that bulging might have not taken place unless it had been exposed to an excessively high temperature, say above $900^{\circ} \mathrm{C}$, for long time, say about $1-2$ years. However, due to involved fire hazard possibility in case of short piece and pigtails though not in case of catalyst tubes being inside fire box, policy should be made carefully for establishing the criteria of bulge-rate acceptance utilizing worldwide experience.

\subsection{Hot collector}

Samples taken from hot collector did not indicate any visible anomaly.

During PT check, however, sample from RH1, showed indication of crack and creep fissures around the nozzle for which $7.4 \%$ bulging was noticed at short piece as shown in Figure 5. Sample, taken from hot-collector with nozzle of RG-42 which had bulging of about $11.4 \%$, did not give any 


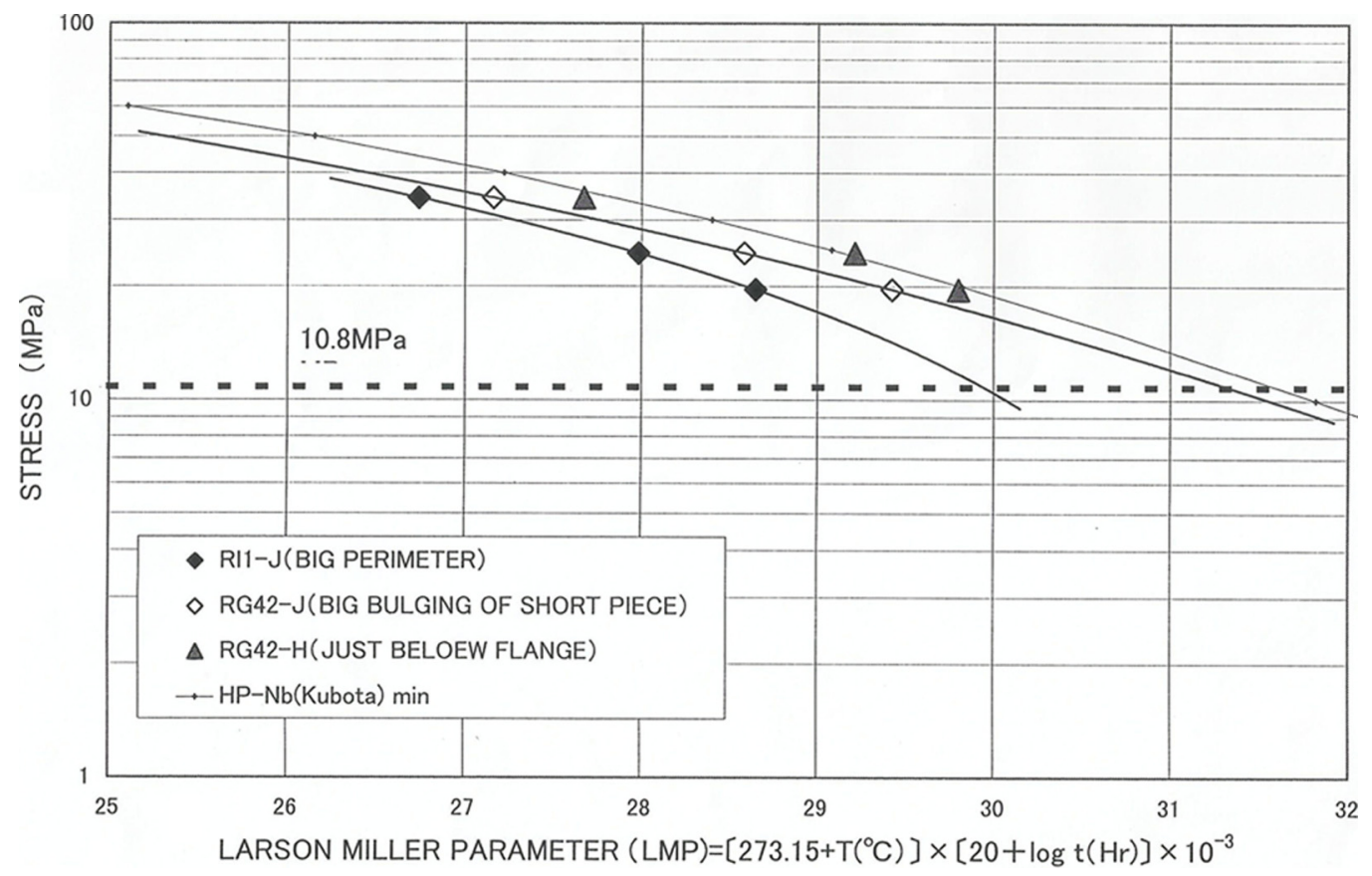

Fig. 2. Creep-life estimation for the catalyst tubes.
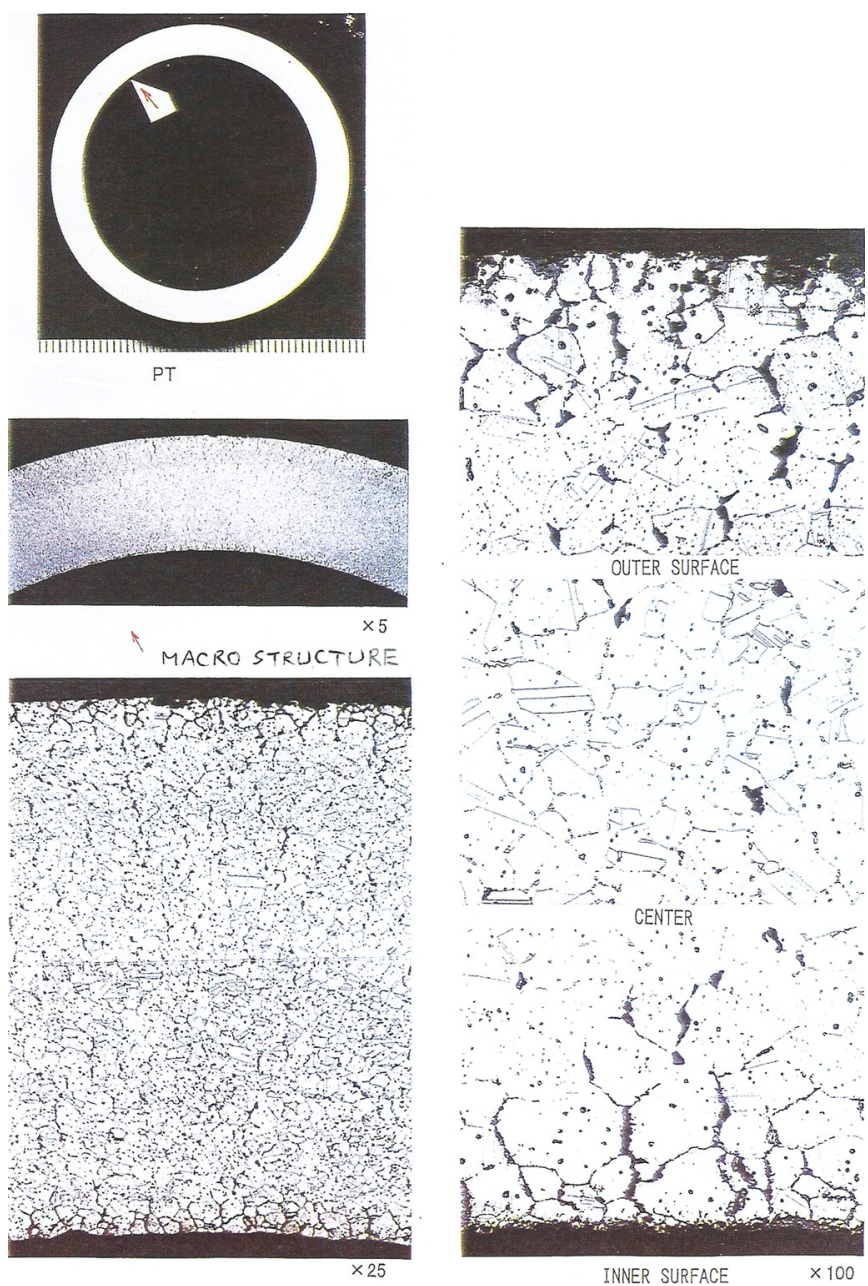

Fig. 3. Result of PT inspection and macro/micro-structural analysis for the short-piece of tube RI-1. indication of crack but showed appreciable creep void. The results here conform to the correlation of bulging in short pieces and presumably exposure to high temperature.

A sample from the failed (the leaked) hot-collector was subjected to creep rupture test, at following conditions:

- temperature: 850 and $900{ }^{\circ} \mathrm{C}$;

- stress: 20, 25, 30, 35, 40 and $45 \mathrm{MPa}$.

The results are shown in Figure 6. Based on the results, remained design life was estimated, for design condition of $24 \mathrm{~kg} / \mathrm{cm}^{2}$ pressure and $888^{\circ} \mathrm{C}$ temperature, to be about $27000 \mathrm{~h}$ against expected $56000 \mathrm{~h}$. Thus, there must have been much higher temperature exposure of the hot-collector, during the course of actual service than its design limit, resulting in pre-mature degradation of its construction material. Though operating conditions may allow continuing the use of same or similar hot collectors for the anticipated remaining-life, these should still be replaced to avoid any fire hazard in future, as thorough integrity assessment is difficult at the site.In current technology scenario, comprehensive examination and analysis techniques, e.g., "internal laser technology with external crawler added with eddy-current functionality", measurement of dimensional expansion "the prime method of detecting normal service creep damage", proprietary creep models, etc., are available to assist in condition-monitoring of the catalyst-tubes with estimation of their remaining-life. Other techniques that rely on creep cracking damage are typically useful only at or very near end of tube life, say when about $80 \%$ damage has already occurred [11].

\section{Conclusions and recommendations}

- the catalyst tubes seem to be less damaged as compared to short pieces and pigtails and can be considered for continued in service for the remaining period of the design life, provided tube-temperature is carefully controlled; 
Creep Strength of Hot Collector

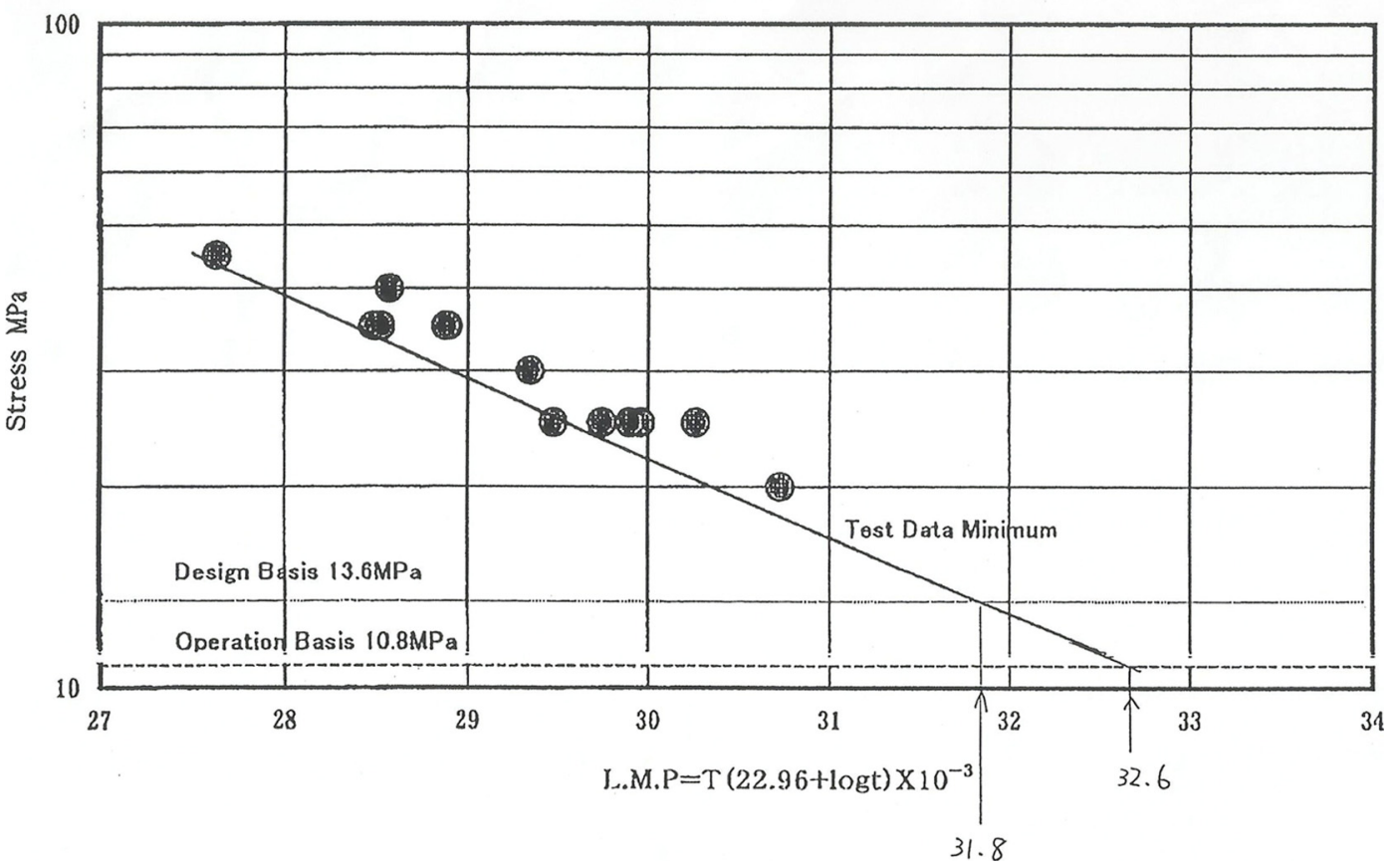

Fig. 6. Residual creep-life estimation for the hot collector.

- no good correlation exists between tube outer perimeter and the degree of metallurgical deterioration of the tubes. This observation might be due to the removal of surface scale by oxidation. Hence, perimeter measurement should not be used as an effective approach of evaluating tube the degradation;

- checking of maximum bulging at the short piece appears to be still an effective tool of evaluating the deterioration of reformer outlet system. Replacement of short piece and pig tails with bulging more than $2 \%$ is enough, to ensure trouble free operation of reformer for the remained design life;

- for hot collectors, die penetrant test and radiographic inspection of weld joints is recommended during plant shutdowns, to ensure header's integrity;

- special attention should be paid to the condition of catalyst as its deterioration is found to cause high temperature of the catalyst tube assembly thus adversely affecting metallurgical integrity. Hence, in plant shutdowns, $\Delta P$ should be regularly checked, to eliminate or minimize the damage at catalyst-tube assembly or outlet piping. Moreover, consistent and uniform heating of tubes will be an added advantage by an effective burner management system.

\section{References}

[1] H. Renner et al., Catalytic reforming of natural gas and other hydrocarbon, in: B. Elvers et al. (eds.), Ullmann's encyclopedia of industrial chemistry, Vol. A2, 5th ed., VCH Publishers, 1985, pp. 143-242
[2] A. Al-Meshari et al., Failure analysis of a primary reformer riser, Hydrocarb. Process. 82 (2003) 76-78

[3] G. Yeh et al., Recover from a stem reformer tube rupture, Hydrocarb. Process. 92 (2013) 85-88

[4] K. Guguloth et al., Remaining life assessment and microstructural studies on service exposed primary reformer tubes of a catalyst converter of an ammonia plant, High Temp. Mater. Proc. 31 (2012) 759-767

[5] R. Singh, Niobium stabilized alloys in steam hydrocarbon reforming, Mater. Perform. 48 (2009) 54-58

[6] S.K. Bhaumik et al., Failure of reformer tube of a ammonia plant, Eng. Fail. Anal. 9 (2002) 553-561

[7] M. Blair et al. (eds.), Heat resistant high alloy steels, Steel casting handbook, 6th ed., Steel Founders Society of America and ASM International, 1995, pp. 22(1)-22(13)

[8] ASM International, ASM Handbook: heat resistant materials, ASM International, Materials Park, 1999

[9] R. Visvanathan et al., Accelerated stress rupture testing for creep life predictions, its value and limitations, J. Press. Vessel Technol. 120 (1998) 105-115

[10] A. Antonello et al., Damage characterization in two reformer heater tubes after nearly 10 years of service at different operations and maintenance conditions, Eng. Fail. Anal. 17 (2010) 1526-1541

[11] R.F. Barry et al., Steam reformer tube life - a case study utilizing advanced inspection techniques and remaining life calculations for Bharat Petroleum Corporation Limited (BPCL), Paper no. 14SI23, NIGIS CORCON 2014 (Intl. Corrosion Conf. \& Expo, organized by NACE Intl. - India, Chap.), Mumbai, November 12-15, 2014

Cite this article as: B. Gaur, Damage analysis and integrity assessment of a few steam-reformer components at a syn-gas plant, Mechanics \& Industry 18, 401 (2017) 